\title{
A INTEGRAÇÃO DOS SISTEMAS DE EDUCAÇÃO SUPERIOR NA EUROPA: DE ROMA A BOLONHA OU DA INTEGRAÇÃO ECONÔMICA À INTEGRAÇÃO ACADÊMICA
}

\section{Mário Luiz Neves de Azevedo}

\section{RESUMO}

Este trabalho trata a respeito do processo de integração dos sistemas de educação superior na Europa, região que, desde o fim da segunda guerra mundial, está procurando eliminar as fronteiras em todos os âmbitos. O Processo de Bolonha, homenagem à universidade mais antiga da Europa, é o nome do conjunto dos eventos (reuniões, resoluções e normas) relativos às medidas de implementação dos princípios da reunião de ministros da educação europeus que ocorreu em Bolonha, em 1999, com a finalidade de construir um espaço europeu de educação superior até o ano 2010, cujos objetivos fundamentais encetam, principalmente, para a competitividade do Sistema Europeu de Ensino Superior frente a outras regiões e para a mobilidade e o emprego no Espaço Europeu. Dessa maneira, analisa-se também o papel dos atores sociais nesse processo e a discussão a respeito da natureza da educação superior: um bem público catalisador da solidariedade internacional ou uma mercadoria a ser explorada na construção de um mercado educativo transnacional.

\section{PALAVRAS-CHAVE}

Política educacional; Processo de Bolonha; Reformas

\section{THE EUROPEAN SYSTEM OF HIGHER EDUCATION INTEGRATION: FROM ROMA TO BOLOGNA OR FROM ECONOMIC INTEGRATION TO ACADEMIC INTEGRATION}

\begin{abstract}
This paper analysis the integration process of higher education system in Europe, region that, since the end of Second World War is trying to eliminate the borders in all scopes. The Process has been named as Bologna's Process, to homage the older Europe's university. It is a set of resolutions, events and rules, related to the implementation measures of the principles resulted of the European ministers meeting, occurred in Bologna in 1999, with the purpose of building an European space of higher education until 2010. The fundamental goals are competitiveness of the front Higher education European system to others regions, mobility and the job in the European Space. It analysis also the social actor's roll in this process and the discussion concerning about of nature of higher education: one very public aspect of the international solidarity or a exploratory merchandise to being explored in the construction of a transnational educational market.
\end{abstract}

\section{KEYWORDS}

Educational politics; Process of Bologna; Higher educational reforms 
A Europa, desde o fim da segunda guerra mundial, está construindo sua integração. A educação superior, sendo um setor estratégico na formação da cultura e para o desenvolvimento europeu, também está implicada.

O Processo de Bolonha, nome do movimento de reforma e integração da educação superior na Europa, é o conjunto dos eventos relativos às medidas de implementação dos princípios da reunião havida em Bolonha em 1999 com a finalidade de construir um espaço europeu de educação superior até o ano 2010, cujos objetivos fundamentais encetam, principalmente, para a competitividade do Sistema Europeu de Ensino Superior frente a outras regiões e para a mobilidade e o emprego no Espaço Europeu, com vistas a harmonizar os sistemas universitários europeus, de modo a equiparar os graus, diplomas, títulos universitários, currículos acadêmicos, e adotar programas de formação contínua reconhecíveis por todos os Estados membros da União Européia.

O primeiro encontro reuniu os Ministros da Educação da França, Alemanha, Itália e Reino Unido, em 1998, e originou o primeiro documento denominado "Declaração de Sorbonne”; a segunda declaração foi assinada, inicialmente, por 29 ministros europeus em Bolonha, em 1999; a Carta de Praga, de 2001, foi chancelada por 33 países; esses mesmos 33 Estados europeus subscreveram, em 2003, o Communiqué de Berlin; a mais recente reunião, em 2005, foi em Bergen (Noruega) e gerou o último documento que foi assinado por 45 países ${ }^{1}$.

Na primeira reunião, sob os auspícios da histórica Universidade de Sorbonne, a decisão fulcral foi o compromisso de harmonizar a emissão de graus acadêmicos. Este propósito inspira-se no Relatório da Comissão Pour un modèle européen d'enseignement supérieur, presidida por Jacques Attali, que sugere a fórmula 3/5/8, ou seja, a formação em nível superior com duração de três anos para a graduação (licenciatura), dois anos para o mestrado e três anos para o doutorado $(3+2+3)$. Segundo esse relatório,

\footnotetext{
Não se pode ter a livre circulação de mercadorias, de capitais, de pessoas, de idéias (...), e manter uma situação em que não é mesmo possível comparar o valor dos diplomas expedidos pelas universidades dos países membros da União Européia (...). Não se pode ter a Europa do emprego sem a Europa da Educação. Sem uniformizar seus sistemas, os países da Europa deverão decidir a respeito de uma certa harmonização dos cursos e dos diplomas e definir um modelo europeu específico, nem burocrático nem submetido ao mercado (ATTALI, 1998, p. 18-19).
}

\footnotetext{
${ }^{1}$ Além desses eventos, ainda houve a reunião do Conselho Europeu em Lisboa (2000) e em Barcelona (2002) que trataram sobre o mesmo assunto.
} 
Para atingir esse resultado, os ministros europeus da educação, em reunião na Universidade de Bolonha, sugeriu o seguinte caminho:

1. Adoção de um sistema de educação superior com normas claras (fácil compreensão) e em que os cursos de graduação possam ser comparados entre si;

2. adoção de um sistema baseado em dois ciclos (graduação e pós-graduação);

3. Estabelecimento de um sistema de créditos;

4. Promoção da mobilidade de estudantes, docentes, pesquisadores e pessoal técnicoadministrativo;

5. Cooperação na avaliação para a garantia da qualidade;

6. Promoção da dimensão européia do ensino superior.

A reunião de Praga, em maio de 2001, com os ministros da pasta educacional, teve como resultado o acréscimo (além dos seis anteriores) de mais três objetivos:

1. Aprendizagem permanente (educação ao longo da vida);

2. Esforço para que haja maior envolvimento dos estudantes nas Instituições de educação superior;

3. Promoção do Espaço Europeu de Ensino Superior.

Além disso, ratificou-se nessa reunião o conceito de créditos ECTS (European Credits Transfer Sistem - Sistema Europeu de Transferência e Acumulação de Créditos), que originalmente já constava no programa europeu de intercâmbio de estudantes universitários Erasmus-Socrates, experimentado por um mais de um milhão de alunos na Europa. O ECTS pode ser considerado um sistema de equivalências e de reconhecimento dos cursos que os estudantes realizam nos países europeus. O ECTS fundamenta-me nos seguintes princípios:

- A comparação do progresso do estudante;

- Os cursos têm a seguinte correspondência crédito x tempo: 1 ano=60 unidades, 1 semestre $=30$ unidades e 1 trimestre $=20$ unidades

- A quantificação de crédito por disciplina condiciona-se a quantidade de horas letivas em classe e o de trabalho extra-classe. Por exemplo, o ano acadêmico tem próximo de 40 semanas, cada aluno freqüenta entre 40 e 45 horas de disciplinas por semana, significando um total de 1600 a 1800 horas por ano. Considerando que um ano acadêmico tem 60 unidades de créditos, um crédito corresponde entre 26 a 30 horas de esforço do estudante.

No encontro de Berlin, reafirmando os compromissos anteriores (Bolonha e Praga), procurou-se salientar a necessidade de maior envolvimento dos estudantes com as iniciativas 
governamentais, a promoção da educação superior européia para os estudantes não-europeus e a criação da Área de Pesquisa Européia, vinculando-a com os estudos em nível de doutorado.

Estes objetivos também foram ratificados pela reunião de Bergen, entre 19 e 20 de maio de 2005, onde avaliou-se que “em nossa reunião em Berlin, (...) nós focalizamos três prioridades - sistema de graus comparáveis, garantia da qualidade e reconhecimento de títulos e períodos (créditos) cursados. A partir dos relatórios apresentados, nós percebemos que houve um substancial progresso nessas três áreas prioritárias” (The European Higher Education Area, 2005, p. 2).

Em 2007, na reunião de Londres, os ministros, preocupados em "responder aos desafios do Mundo globalizado" e em busca da competitividade e da capacidade de atração de estudantes, entretanto, baseando-se nos princípios da liberdade acadêmica, da igualdade de oportunidades, da democracia e da autonomia universitária, reafirmaram o compromisso de construir o Espaço europeu de Educação Superior até o ano de 2010.

\title{
A EUROPA DO CONHECIMENTO: POLÍTICA PÚBLICA DE UM META-ESTADO PARA UM META-CAMPO UNIVERSITÁRIO
}

Desenvolve-se o presente trabalho, partindo-se do pressuposto de que a Universidade, ou melhor, o sistema de educação superior de cada país integrado ao Bloco Europeu pode ser considerado como um campo social. Isto é, trata-se de um espaço estruturado de posições onde os atores sociais travam relações, fazem alianças e lutam entre si e com atores externos capazes de interferir no arranjo espacial desse campo. Conforme Bourdieu,

\begin{abstract}
A noção de espaço contém, em si, o princípio de uma apreensão relacional do mundo social: ela afirma, de fato, que toda a realidade que designa reside na exterioridade mútua dos elementos que a compõem. Os seres aparentes, diretamente visíveis, quer se trate de indivíduos quer de grupos, existem e subsistem na e pela diferença, isto é, enquanto ocupam posições relativas em um espaço de relações que, ainda que invisível e sempre difícil de expressar empiricamente, é a realidade mais real (ens realissimum, como dizia a escolástica) e o princípio real dos comportamentos dos indivíduos e dos grupos. (BOURDIEU, 1996, p. 48-49).
\end{abstract}

\section{O ESTADO: UM CAMPO DE LUTAS}

Deve-se ter em conta que o Estado é um meta-ator das políticas públicas ${ }^{2}$, pois, por excelência, é o organizador, executor e garantidor dessas mesmas políticas. Qualquer estudo sobre políticas públicas, como, por exemplo, o Processo de Bolonha, deve vir acompanhado

\footnotetext{
${ }^{2}$ A própria União Européia pode ser considerado um Estado transnacional, ou seja, os países reunidos na Comunidade Européia cedem parte de sua soberania com vistas à construção de uma região integrada em termos econômicos, sociais , políticos, culturais e educacionais.
} 
de um debate sobre o conceito de Estado. Isto porque o Estado é uma construção histórica e uma criação própria da luta entre classes e atores sociais, dessa forma, o Estado é um campo de contradições e lutas, logo as políticas geradas no campo estatal, também, carregam a mesma marca, são fruto da luta entre as classes sociais e entre os atores implicados, isto é, as políticas públicas portam o consenso e a contradição das diversas forças que agem na sociedade.

A dificuldade de tratar sobre a questão do Estado foi reconhecida inclusive pelos mais seguros teóricos sobre o assunto, a exemplo de Lênin, que, em conferência na Universidade de Sverdlov, em 10 de julho de 1919, asseverou: “(...) dificilmente se encontrará outra questão tão embrulhada, deliberadamente ou não pelos representantes da ciência, da filosofia, da jurisprudência, da economia política e da publicística burguesas, como a questão do Estado” (SVERDLOV, 1979, p. 177).

Marx e Engels, para retornar um pouco mais na tradição de esquerda de tentar compreender o Estado, no conhecido "Manifesto do Partido Comunista”, texto aprovado pela AIT - Associação Internacional dos Trabalhadores - fazem a seguinte definição de Estado: “O governo moderno não é senão um comitê para gerir os negócios comuns de toda classe burguesa” ([s.d], p. 23).

Somente para ilustração histórica, deve-se lembrar que o Estado do século XIX é prioritariamente coativo e é esta a definição que se encontra no Manifesto do Partido Comunista. Além disso, a expressão “negócios comuns” da classe burguesa fornece a percepção que a sociedade, não obstante possuir a contradição entre as classes fundamentais, tem, na classe dominante, frações com interesses diversos.

Gramsci, reconhecido por muitos como o marxista mais influente no ocidente no século XX, desenvolveu o conceito de hegemonia e produziu um original conceito de Estado. Para Gramsci, o Estado não se impõe somente pela força, mas, também, pela ideologia e pela cultura: “O Estado tem e pede o consenso, mas também 'educa' este consenso utilizando as associações políticas e sindicais, que, porém são organismos privados deixados à iniciativa particular da classe dirigente” (GRAMSCI, 1989, p. 145).

A Sociedade Civil, ou seja, o conjunto das instituições civis que formam a opinião pública, que criam e difundem a ideologia e a cultura, representa o pólo do consenso no Estado. Já a Sociedade Política desempenha o papel da coerção. Dito de outro modo, a Sociedade Política detem o monopólio da violência e a Sociedade Civil é a congregadora dos 
vetores da persuasão e do convencimento. Sociedade Civil e Sociedade Política são as duas expressões fundamentais contidas na fórmula de Estado de Gramsci (força + hegemonia).

A hegemonia é a substância principal de união do bloco histórico, ou seja, a hegemonia funciona como uma liga para a construção do amálgama sócio-político que dirige uma sociedade. Gramsci recorre a Marx, segundo o qual, as idéias quando assimiladas pelas massas, transformam-se em força material, e faz a eficiente analogia com o conceito de bloco histórico. A classe dirigente do bloco histórico detém a supremacia. Conforme Gruppi, "Supremacia é domínio e direção. Pode-se dizer que é domínio e hegemonia" (1980, p. 79).

Por fim, para tentar completar essa preliminar reflexão sobre o conceito de Estado, recorre-se a Pierre Bourdieu. Para o sociólogo francês,

O Estado é resultado de um processo de concentração de diferentes tipos de capital,
capital de força física ou de instrumentos e coerção (exército, polícia), capital
simbólico, concentração que, enquanto tal, constitui o Estado como detentor de uma
espécie de metacapital, com poder sobre os outros tipos de capital e sobre seus
detentores (...). Segue-se que a construção do Estado está em pé de igualdade com a
construção do campo do poder, entendido como o espaço do jogo no interior do qual
os detentores de capital (de diferentes tipos) lutam particularmente pelo poder sobre o
Estado, isto é, sobre o capital estatal que assegura o poder sobre os diferentes tipos de
capital e sobre sua reprodução (notadamente por meio da instituiçãa escolar).
(BOURDIEU, 1996, p. 99-100).

Além disso, Bourdieu elabora uma curiosa imagem do Estado, descrevendo-o como dotado de mão direita e mão esquerda, sendo que, no Estado capitalista, em geral, ocorre o predomínio da mão direita do Estado sobre a mão esquerda:

\footnotetext{
Eu penso que a mão esquerda do Estado tem o sentimento que a mão direita não sabe mais ou, pior, não quer mais verdadeiramente saber o que a mão esquerda faz. Em todo caso, a mão direita se recusa a pagar a conta. Uma das maiores razões do desespero das pessoas está no fato que o Estado se retirou ou está se retirando de um certo número de setores da vida social que se incumbia e que se encarregava: a habitação popular, a rádio e a televisão públicas, a escola pública, os hospitais públicos etc. (BOURDIEU, 1998, p. 10).
}

Dessa forma, para se compreender as políticas públicas, deve-se ter a clareza que o Estado não é algo homogêneo, é, na realidade, um campo de contradições e lutas. Em poucas palavras, o Estado, campo social ocupado por atores sociais com interesses comuns e, também, contraditórios, opera políticas públicas que vão influenciar o conjunto da população a ele subordinado. 


\title{
O PROCESSO DE BOLONHA
}

Depara-se com uma novidade complexa ao se deparar com o Processo de Bolonha, pois trata-se de uma política pública que ultrapassa as fronteiras territoriais de um Estado clássico, que abrange a Europa ampliada, atingindo mais de quatro dezenas de diferentes países. O Processo de Bolonha é uma política pública transnacional dirigida, em última instância, por um meta-Estado, que é a União Européia, com vistas a regular um meta-campo social, o campo universitário/científico europeu, que, a exemplo de qualquer outro campo social, caracteriza-se por ser um espaço estruturado de posições, cujos atores, permanentemente, travam relações, fazem alianças e lutam entre si, bem como se relacionam com atores externos que, apesar da autonomia universitária, são capazes de interferir no arranjo espacial desse mesmo campo. Conforme Bourdieu,

\begin{abstract}
Um dos grandes paradoxos dos campos científicos é que eles devem, em grande parte, sua autonomia ao fato de que são financiados pelo Estado, logo colocados numa relação de dependência de um tipo particular, com respeito a uma instância capaz de sustentar e de tornar possível uma produção que não está submetida à sanção imediata do mercado (...). Essa dependência na independência (ou o inverso) não é destituída de ambigüidade, uma vez que o Estado que assegura as condições mínimas da autonomia também pode impor constrangimentos geradores de heteronomia e de se fazer de expressão ou de transmissor de pressões de forças econômicas (...) das quais supostamente libera. (BOURDIEU, 2004, p. 55).
\end{abstract}

O Processo de Bolonha, dessa maneira, é um complexo de relações e regulações localizado em uma região, a Europa, caracterizada pela diversidade cultural, social, política e econômica. A União Européia, diga-se de passagem, é inaugurada por um tratado econômico, assinado em Paris, em 1951, chamado de “Comunidade Européia do Carvão e do Aço” (CECA). Os seis países fundadores (Alemanha, Bélgica, França, Itália, Luxemburgo e Holanda) deixaram impresso no preâmbulo as premissas desse acordo, que entrou em vigor em 1952:

\begin{abstract}
Convencidos de que a contribuição que uma Europa organizada e vibrante pode aportar à civilização é indispensável a manutenção de relações pacíficas; conscientes de que a Europa somente se construirá por concretas realizações, criando uma solidariedade de fato, e pelo estabelecimento de bases comuns de desenvolvimento econômico (...). Decididos a substituir as seculares rivalidades por uma essencial fusão de seus interesses, a fundar pela instauração de uma comunidade econômica as primeiras bases de uma comunidade com o sentido mais amplo e profundo entre os povos que longamente se opuseram em disputas sangrentas e, por fim, a lançar, a partir desse momento, as bases de instituições capazes de orientar um destino compartilhado (MATHIEU, 1998, p. 5).
\end{abstract}

Foram assinados, ainda, dois tratados em Roma, em 1957, que criaram, o primeiro, a “Comunidade Européia de Energia Atômica” (CEEA) e, o segundo, demonstrando a 
importância da questão econômica, a “Comunidade Econômica Européia” (CEE), ambos estabelecendo que, a partir de 1958, os seis países signitários estavam "determinados a estabelecer os fundamentos de uma união cada vez mais estreita entre os povos europeus” ibid., p. 6). A longa experiência de integração com base nesses dois tratados de integração, que aprova inclusive a livre mobilidade de trabalhadores em territórios europeus conhecidos como espaço Shengen, permitiu a assinatura do importante Tratado de Maastricht, de 1992, em vigor desde 1993, quando governantes de doze países ${ }^{3}$ acordam uma nova etapa para a integração da Europa, que passou a se chamar de "União Européia” (UE), entre seus objetivos, destaque-se o de "Promover o progresso econômico e social equilibrado e durável, notadamente pela criação de um espaço sem fronteiras interior, pela reforço da coesão econômica e monetária, comportando, enfim, uma moeda única” (MATHIEU, 1998, p. 8).

Percebe-se, dessa forma, que o processo de integração da União Européia, que desde 01.05.2004 conta com 25 países, é marcado por alavancagens ambivalentemente relacionadas, primeiro, com o sentido de por fim às rivalidades entre os Estados europeus e, segundo, com a instauração de um mercado econômico comum. De modo que a mélange de capitais econômicos possa por fim a constrangimentos de concorrência política históricos. Mathieu recolhe um extrato da declaração dos formuladores da integração européia, J. Monnet e R. Schuman, em 05.05.1950:

\footnotetext{
para que a paz possa verdadeiramente ter sua chance, é necessário inicialmente que se tenha uma Europa [integrada]. Cinco anos, dia-a-dia, após a capitulação da Alemanha, a França cumpre o primeiro ato decisivo, associando-se à Alemanha, para a construção européia (...). Esta proposta [CECA] significa os primeiros passos concretos de uma federação européia, que é indispensável para a paz (MONNET; SCHUMAN,1950 apud MATHIEU, 1998, p. 109).
}

Enfim, a União Européia, potencialmente, antes de ser um simples mercado comum econômico, é um projeto de solidariedade e de paz. Porém, a idéia de extingüir a concorrência sanguinária entre às nações pode estar cedendo lugar à lógica da construção de um espaço econômico e de concorrência entre agentes do capital.

No que se refere à construção do espaço europeu de educação superior, apesar da publicação de documentos de organismos europeus, como a UNESCO, que exaltam a importância da internacionalização solidária da educação superior, há think tanks, como a

\footnotetext{
${ }^{3}$ Aderiram aos tratados da União Européia, além dos seis países já mencionados, a Dinamarca, Irlanda e Reino Unido, em 1973; a Grécia, em 1981; a Espanha e Portugal, em 1986; o território da antiga Alemanha Oriental, em 1990, a Áustria, a Finlândia e a Suécia, em 1995. Atualmente, como os novos aderentes, a União Européia conta com 25 países.
} 
Organização Mundial do Comércio (OMC), por intermédio do GATS (Acordo Geral sobre Comércio de Serviços), que promovem a transnacionalização, com caráter comercial, da educação universitária. Conforme salienta Dias Sobrinho

\begin{abstract}
Nessas declarações (do Processo de Bolonha) o que prevalece não é o sentido explicitamente comercial. O propósito central anunciado no texto é consolidar amplos processos interativos de incorporação de todas as dimensões científicas, pedagógicas, culturais e globais da educação superior. Assim, a educação superior estaria efetivamente enriquecendo a cidadania européia e aprofundando a consciência de que todos os europeus compartilham valores e pertencem a espaços culturais e sociais comuns (...). Porém, na prática nem sempre prevalecem os bons princípios de caráter democrático e participativo (...). Não se trata só de cooperação, mas também de uma forte competição, como costuma ocorrer nos âmbitos regidos pela lógica de mercado (...). Os principais temores se ligam especialmente à mercantilização da educação superior de corte transnacional, que pode passar a ser formalmente regulada pelo Acordo Geral de Comércio sobre Serviços (GATS), capítulo da Organização Mundial do Comércio (OMC). (DIAS SOBRINHO, 2005, p. 186).
\end{abstract}

Essa preocupação, registrada por Dias Sobrinho, de mercadorização da educação superior, de forma transnacional, é percebida como um risco pelos dirigentes das Instituições de Educação Superior (IES). Segundo relatório preliminar a respeito da internacionalização acadêmica (IAU 2005 Internationalization Survey), produzido a pedido da Associação Internacional das Universidades, “A comercialização e a mercadorização da educação superior é considerada como o risco número um para todas as IES (...)” (KNIGHT, 2006, p. 18).

Esse temor é justificável, pois, em 2006, dois respeitáveis think tanks UNESCO e OCDE publicaram em conjunto o texto Directrices en materia de calidad de la educación superior a traves de las fronteras, em que há a preocupação com a qualidade do ensino transnacional em tempos de mobilidade acadêmicas e de liberalização dos serviços educacionais, conforme é previsto no GATS da OMC. Para oferecer garantia de qualidade dos “serviços prestados”, propõe-se que agências de certificação e de garantia da “qualidade”, sejam os avalizadores dos provedores transnacionais no grande mercado universitário. A UNESCO e a OCDE afirmam que esse é "um documento oportuno que trata sobre assuntos fundamentais relativos à educação superior em uma sociedade mais mundializada" (UNESCO/OCDE, 2006, p. 4). O documento também sugere, para além da autonomia universitária, a promoção de organismos que seriam os garantidores da qualidade de ensino e da convalidação de diplomas: “Além da gestão interna da qualidade das instituições e dos provedores de educação superior, mais de 60 países adotaram um dispositivo externo de 
garantia da qualidade e convalidação” (UNESCO/OCDE, p. 18). Aconselhando, enfim, que esses organismos transnacionais

procurem seus dispositivos de garantia da qualidade e convalidação abarquem as distintas
modalidades de ensino transfronteiriço (...). Subscrevam acordos de convalidação, tomando
como base a confiança e a compreensão mútua (...). Contemplem a possibilidade de adotar
procedimentos relativos à composição internacional das bancas de examinação (...),
empreender projetos conjuntos de avaliação que sirvam para melhorar a comparabilidade
das atividades de avaliação de diferentes organismos de garantia de qualidade e
convalidação (UNESCO/OCDE, 2006, p. 19-21).

Esta lógica enfraquece o conceito de educação como um bem público que acompanha a construção da Europa do Bem-Estar. Mas, não faltam manifestações de resistência de atores sociais que defendem uma Europa de solidariedade, como expressa a Associação Internacional das Universidades, entidade com sede em prédios da UNESCO em Paris, que preparou um documento, em conjunto com a Associação das Universidades e Faculdades do Canadá (AUCC), com o Conselho Americano de Educação (ACE) e com o Conselho de Acreditação de Educação Superior (CHEA), defendendo que a internacionalização não pode ferir o princípio que a educação é um bem público:

Nós acreditamos que as políticas e os tratados internacionais transfronteiriços na área de educação superior, particularmente no contexto da OMC e outros tratados similares, devem possuir limitações. Esses tratados devem respeitar o direito de governos e organismos nacionais de regular seus sistemas de educação superior. (IAU, 2004, p. 2).

Paradoxalmente, o Processo de Bolonha pode estar servindo a propósitos contraditórios. De um lado, as forças progressistas européias que defendem uma integração baseada na internacionalização solidária da educação superior; de outro, os grupos e atores sociais que procuram extrair da integração acadêmica compromissos da União Européia com a transnacionalização, de marca privatista, de serviços educacionais universitários. Para melhor compreensão e na tentativa de arrematar a discussão, apresenta-se, a seguir, a fundamentação do Processo de Bolonha

\section{OS FUNDAMENTOS DO PROCESSO DE BOLONHA (à guisa de considerações finais)}

Uma política pública é um rol de procedimentos governamentais que tem a finalidade de (des)regular ou reformar um setor ou serviço público. A sustentação de determinada política pública pressupõe, ao menos, quatro fundamentos que, para facilitar o entendimento, podem ser classificados em dois conjuntos: os fundamentos estratégicos e os fundamentos prévios. 
Os fundamentos de política interna e de política externa formam o conjunto denominado de fundamentos estratégicos, os quais são as bases de garantia de um possível cenário em que os atores sociais podem vislumbrar mudanças no campo social e na disposição estrutural do espaço em disputa.

O outro conjunto de fundamentos que formam a base explicativa das políticas públicas são os fundamentos prévios, que seriam aqueles que fornecem as condições para o encaminhamento de dada política pública, isto é, são as fundações que sustentam o sucesso junto à opinião pública das propostas de reforma (de mudança). Os fundamentos prévios são formados pelos fundamentos ideológicos e pelos fundamentos críticos, ambos são pressupostos indispensáveis para a formação de um novo consenso em torno de políticas públicas de reforma. Para maior clareza, seguem as conceituações dos fundamentos que justificam a construção do Processo de Bolonha.

1. Fundamentos de política interna: as políticas públicas causam mudanças no espaço de disposição dos atores sociais. O campo social de que trata o objeto de determinada política pública sofre rearranjos segundo a correlação de forças existente e, de acordo, com o incentivo aos atores sociais do campo social em conformação.

Vale lembrar que os atores sociais estão em luta constante por espaços. A implementação de novas políticas apresenta-se como um momento de oportunidades de deslocamentos políticos no campo social. Este movimento pode significar ascensão, descenso ou mesmo "desclassificação" para os atores sociais envolvidos. O Processo de Bolonha, como política pública destinada à integração dos vários sistemas de educação superior na Europa, gerará (re)classificações no que será o grande campo universitário europeu. Pois, ao mesmo tempo em que se sinaliza para a construção de uma Europa de fraternidade científicaacadêmica, também, demonstra-se a lógica da competição e, mesmo, da construção de um mercado da educação superior europeu. Nesse sentido, os atores sociais que mais seriam beneciados seriam aqueles que detêm (ou almejam) características internacionalizadas.

Dessa forma, por exemplo, não é irrelevante mencionar que, para além do domínio científico, os acadêmicos capazes se expressarem em língua inglesa, integrados a grupos de pesquisa internacionais e com produção científica internacional, tornam-se atores dominantes no Processo de Bolonha. Ainda, de Acordo com Dias Sobrinho, 
A grande meta desses países é promover, até 2010, uma transformação conjunta das estruturas da educação superior européia, a partir de um marco de referência comum em termos de titulação níveis de ensino, currículos, sistema de convalidação de créditos, mecanismos de garantia de qualidade e fé pública, facilitação da mobilidade internacional, enfim, uma reforma que seja capaz de superar barreiras culturais, de idiomas e modelos educativos desse nível e torná-lo mais eficiente e competitivo. Em resumo, trata-se de eliminar as barreiras que impedem a livre circulação de capitais, mercadorias, conhecimentos e pessoas, mais propriamente, dos profissionais (DIAS SOBRINHO, 2005, p. 175-176).

Outros atores sociais, como os provedores de educação superior, principalmente as universidades que assumiram um caráter empresarial-mercadológico, adaptadas ao livre jogo do mercado, a exemplo das universidades inglesas, também serão beneficiadas pela implementação da agenda contida no Processo de Bolonha. A esse respeito, deve-se notar que, no ano acadêmico 2001-2002, a educação superior inglesa recebeu somente de fundos privados, principlamente formados por taxas acadêmicas, o montante de 4,699 bilhões de Libras Esterlinas, equivalendo 39,7\% do total. É importante salientar que, segundo estudos do HEFCE (Higher Education Funding Council for England) e OCDE (Organização para Cooperação e Desenvolvimento Econômico), publicados em 2004, a população acadêmica inglesa alcança 1,8 milhão de estudantes e, desses, havia 243.000 estudantes estrangeiros, representando $12 \%$ do total. Somente os estudantes não-ingleses aportaram aos fundos universitários 763 milhões de Libras, ou seja, 6\% de todo o orçamento para a educação superior inglesa que, de acordo o HEFCE, atinge 11,834 bilhões de Libras (HEFCE/OECD, 2004, p.3-10).

O Processo de Bolonha pode, com relação a atração de estudantes, segmentar o campo universitário europeu. Alberto Amaral, pesquisador do Centro de Investigação sobre Política de Educação Superior (CIPES), de Portugal, alertou em conferência proferida em São Paulo, em 26.04.2005, que

é possível que se crie uma Área Européia de Ensino Superior a duas ou mais velocidades, com algumas instituições de elite a concentrar os recursos de investigação e pós-graduação (...). As outras instituições serão universidades nacionais ou regionais 'de transmissão de conhecimentos', concentrando esforços no ensino do $1^{\circ}$ ciclo de Bolonha [licenciatura de três anos] que será massificado passando a substituir a formação ao nível secundário (CIPES, 2005).

Com esses poucos exemplos, já é possível perceber a movimentação espacial no mega-campo universitário que enseja o Processo de Bolonha. Uma reforma de tal magnitude causará, seguramente, mudanças no espaço de disposições sociais, gerando ascensões e descensos significativos dos atores sociais envolvidos no campo da educação superior europeu. 
2. Fundamentos de política externa: muitas vezes as razões de ordem externa têm sido as mais valorizadas pelos investigadores de políticas públicas, principalmente quando o objeto de análise são relacionados aos países de capitalismo dependente, entretanto mesmo os países centrais, também, balizam suas políticas públicas com relação aos agentes, países e regiões exteriores. Os governantes de Estados dependentes esperam adquirir credibilidade (confidence building) junto aos países centrais, já as autoridades governamentais dos países e blocos dominantes preocupam-se com a construção de vantagens diante de seus competidores. A declaração conjunta dos ministros da educação europeus reunidos em Bolonha, em 19 de junho de 1999, que sela o início do Processo de Bolonha, é contundente nesse sentido:

O rumo foi colocado na direção certa, dentro dos objetivos apropriados. A obtenção
de maior compatibilidade e de maior comparabilidade dos sistemas do ensino requer,
no entanto, uma contínua energia para se cumprir plenamente (...). Deve-se ter em
conta o objetivo de elevar a competividade internacional do sistema europeu do
ensino superior. A vitalidade e a eficiência de qualquer civilização pode medir-se pela
atração que a sua cultura exerce sobre os outros países. Precisamos de assegurar que
os sistema europeu de ensino superior consiga adquirir um grau de atração mundial
semelhante ao das nossas extraordinários tradições cultural e científica [sem grifos no
original] (CIPES, 2005, p. 2)

3. Fundamentos ideológicos: no mundo do capital, toda política pública possui um revestimento ideológico. As políticas Públicas, por exemplo, comprometidas com a mercadorização pressupõe uma forte inculcação de valores individualistas. O argumento ideológico é, por exemplo, o individualismo elevado à condição de teoria, pois, conforme o pesquisador indiano Jandhyala Tilak, criticando o laissez-faireism na educação superior, “O papel da educação superior é reinterpretado e redefinido (...). Agora com as privatizações, (as tradicionais) funções estão sendo substituídas por motivos financeiros” (2005, p. 98). O núcleo irradiador da ideologia individualista, em grande medida, é uma fração social que cultiva sentimentos não-solidários. Conforme aponta Bourdieu, em contenda teórica com um dirigente do mundo financeiro,

\begin{abstract}
A interpelação que eu lancei (...) é continuamente mal compreendida porque está posta no âmbito da lógica neoliberal (...). Segundo esta visão. Admite-se que a integração monetária, simbolizada pela criação do Euro, é uma premissa obrigatória, condição necessária e suficiente para a integração política da Europa. Em outros termos, entende-se que a integração política da Europa deslanchará, ilutavelmente, da integração econômica (BOURDIEU, 1998, p. 67).
\end{abstract}

Entretanto, o argumento ideológico tem maior poder de convencimento onde existe crise no setor em reforma ou o anseio de mudança é crítico. O Processo de Bolonha chama a 
atenção para a instauração de um sistema europeu universitário que potencializaria a mobilidade acadêmica e a empregabilidade na Europa. O conceito de empregabilidade por si só é o suficiente para evidenciar o componente ideológico constante nos documentos embasadores do Processo de Bolonha. De acordo com Amaral, “é introduzido o conceito de 'empregabilidade', distinto do conceito de 'emprego', ou seja, a introdução de uma responsabilidade individual que substitui uma responsabilidade de Estado” (2005). Na realidade, isto significa uma radicalização da teoria do capital humano, pois, atualmente, não se trata de uma promessa de rendimentos superiores para os trabalhadores escolarizados, mas uma imposição para que os mesmos estejam em "educação contínua" para não perderem a condição de "empregabilidade".

4. Fundamento crítico: O fundamento crítico representa a real situação de crise do setor. Em países do terceiro mundo essa crise pode se revelar na deterioração dos serviços públicos, na apropriação de porções da esfera pública por setores privados e no descontrole do Estado sobre atividades e serviços públicos. Nos países centrais, a crise pode se revelar no handicap ou no gap de vantagens comparativas diante de seus concorrentes mundiais. Diante do predomínio dos Estados Unidos da América, secundariamente da Austrália e Nova Zelândia, na atração de estudantes estrangeiros, o Processo de Bolonha tem entre seus principais objetivos a conquista de capacidade de atração de estudantes não europeus.

O relatório “A Declaração de Bolonha e o sistema de graus do ensino superior”, a respeito da situação de Portugal no processo de integração, reconhece que a longa duração dos cursos de graduação é um fator negativo frente a outros países:

\begin{abstract}
A redução da duração da formação não é nem um objectivo em si, nem um resultado imediato da Declaração de Bolonha. No entanto, não se poderá deixar de questionar a duração dos estudos em Portugal, em confronto com o que se passa noutros países (...). Está comprometida a capacidade de atrair estudantes de outros países e os estudantes portugueses poderão ser levados a optar por estudar em outro país. Para além disso, está por provar que os sistemas que contemplam uma menor duração (...) tenham uma qualidade inferior (PORTUGAL, 2001, p. 2-3).
\end{abstract}

A preocupação das autoridades portuguesas também pode ser uma preocupação crítica para grande parte das universidades européias. A solução proposta pelo Processo de Bolonha, inspirado no Relatório Attali, é homogeneizar os cursos superiores na fórmula 3-5-8, ou seja três (3) anos para a graduação, 2 (dois) para o mestrado e três (3) para o doutorado. Essa 
fórmula pressupõe a adoção do sistema de créditos compatíveis (ECTS), conforme já apresentado no presente texto.

Os fundamentos ideológicos e fundamentos críticos, aqui chamados de fundamentos prévios, são a cara e a coroa de uma mesma moeda. O ideológico, mesmo sendo a falsificação da realidade, funciona como um revestimento discursivo de um concreto em crise. As proposições de reforma somente encontram eco onde há problemas reais para serem resolvidos e onde há um discurso ideológico apropriado para o convencimento da opinião pública.

Resta, enfim, continuar a direcionar a atenção para a construção da integração européia. Pois, no que se refere à educação superior e o Processo de Bolonha, a correlação de forças no meta-campo político, que é a própria União Européia, é a condicionante fundamental que, por derradeiro, determinará se prevalecerá a solidariedade na Europa do conhecimento ou a lógica de mercado no sistema europeu de Educação Superior.

\section{REFERÊNCIAS}

AMARAL, A. Reformas na União Européia e sua implementação: balanço e perspectivas. São Paulo. Disponível em: www.mec.gov.br. Acesso em: 15 dez. 2005.

ATTALI, J. Pour un modèle européen d'enseignement supérieur. Rapport de la Comission présidée par Jacques Attali. Paris: Éditions Stock, 1998.

BOURDIEU, P. Contre-feux. Paris:Éditions Liber-Raisons d'Agir, 1998.

Razões práticas: sobre a teoria da ação. Tradução Mariza Corrêa. Campinas:

Papirus, 1996.

. Os usos sociais da ciência: por uma sociologia do campo científico. São Paulo:

UNESP, 2004.

DIAS SOBRINHO, J. Dilemas da educação superior no mundo globalizado. Sociedade do conhecimento ou economia do conhecimento? São Paulo: Casa do Psicólogo, 2005.

GRAMSCI, A. Maquiavel, a política e o Estado moderno. Rio de Janeiro: Civilização Brasileira, 1989.

GRUPPI, L. O Conceito de hegemonia em Gramsci. Rio de Janeiro: Edições Graal, 1980.

HEFCE/OECD. Financial management and governance in HEIs: England. Londres.

Disponível em: www.hefce.ac.uk. Acesso em: 7 jul 2005. 
IAU (Internacional Association of Universities). Sharing quality higher education across borders: a statement on behalf of higher education institutions worldwide. Paris, 2004. Disponível em: www.unesco.org/iau. Acesso em: 22 jan. 2006.

Internationalization Survey (preliminary findings report). Paris. Disponível em: www.unesco.org/iau. Acesso em: 22 jan. 2006.

KNIGHT, J. Internationalization Survey (preliminary findings report). Paris. Disponível em: www.unesco.org/iau. Acesso em 22 jan 2006.

LÊNIN, V. Sobre os Sindicatos. São Paulo: Polis, 1979.

MARX, K.; ENGELS, F. O manifesto do partido comunista. Obras Escolhidas. São Paulo: Alfa-Omega, s/d. Volume 1.

MATHIEU, Jean-Luc. L’Union Européenne. Paris: PUF, 1998.

PORTUGAL. A declaração de Bolonha e o sistema de graus do ensino superior: bases para uma discussão. Lisboa: 2001. Mimeo

Realising the European Higher Education Area. Communiqué of the Conferenceof European Ministers Responsible for Higher Education, Berlin, 19 Sep. 2003. Disponível em: http://eees.universia.pt. Acesso em: 15 jul. 2005.

SILVA JUNIOR, J. R.; OLIVEIRA, J. F.; MANCEBO, D. (Org.). Reforma universitária: dimensões e perspectivas. Campinas: Editora Alínea/ANPEd, 2006. (Coletânea Políticas Universitárias-GT 11 “Política de Educação Superior”).

The Bologna Declaration. Communiqué of the Conference of European Ministers Responsible for Higher Education, Berlin, 19 Jun.. 1999. Disponível em: http://eees.universia.pt. Acesso em: 15 jul. 2005.

The European Higher Education Area: Achieving the Goals. Communiqué of the Conference of European Ministers Responsible for Higher Education, Bergen, 19-20 May 2005. Disponível em: http://eees.universia.pt. Acesso em: 15 jul. 2005.

The Sorbonne Declaration. Communiqué of the Conferenceof European Ministers Responsible for Higher Education, Berlin, 1998. Disponível em: http://eees.universia.pt. Acesso em: 15 jul. 2005.

TILAK, J. Are we marching towards laissez-faireism in higher education development? In: IAU. The Wealth of Diversity: The Role of Universities in Promoting Dialogue and Development. 2004 General Conference. São Paulo: Edusp/IAU, 2005.

Towards the European Higher Education Area: responding to challenges in a globalised world. London Communiqué. London: 18 may 2007. Disponível em: http://www.cicic.ca. Acesso: 1 out. 2007. 
UNESCO/OCDE. Directrices en materia de calidad de la ecucación superior a través de las fronteras. Paris: 2006. Extraído de www.unesco.org. Acesso em 20 mar 2006.

Nota do autor sobre o texto:

* Com poucas alterações, este texto foi originalmente apresentado na 29a. Reunião Anual da ANPEd (2006) e, por iniciativa do GT 11 "Política de Educação Superior”, foi publicado, pela Editora Alínea, na coletânea Políticas Universitárias, organizada por João dos Reis Silva Jr; João Ferreira de Oliveira e Deise Mancebo. 